\title{
Situational analysis of pediatric residency training program in Indonesia
}

\author{
Srisuparyati Soenarto, Ova Emilia
}

\begin{abstract}
Background Over the last twenty years, higher education, particularly pediatric residency training, has changed dramatically. A question arises whether the pediatric residency training conducted in Indonesia today has been set up to meet the changing as well as the community needs.

Objective To evaluate whether the pediatric residency training program in Indonesia today has met the changing as well as the community needs.

Methods Twelve centers with pediatric training program in Indonesia were involved in this study. Each institution had various number of respondents, with a total of 42 respondents. A structured questionnaire with open responses was selected to ensure the variety and flexibility of responses. The questionnaires included statements which encompassed areas such as curriculum, training and educational system, and alumni achievement of educational objectives. Continuous content analysis of the responses was made.

Results Coverage was considered adequate by $80 \%$ of respondents and was suggested to be continuously updated to be in line with existing national problems but not yet considered international standard. Additional knowledge and competence proposed by the respondents are mollecular biology, genetics, generic skills, communication skills, and introduction to sophisticated instruments. The length of the existing program was appropriate. Graduate knowledge was sufficient and fulfilled pediatric standards. Current program was different from that of the past. The objectives are comprehensible. The placement of trainees enabled them to follow each division in a spiral fashion (at least three times during the training). Conclusion The curriculum content of the training process was continuously updated to be inline with existing national problems. Additional knowledge, and competence, and the present length of study was considered appropriate. Graduate knowledge is sufficient and fulfills pediatric standards. Furthermore, the objectives of the current program are clearer and placement of trainees enables them to follow each division at least three times [Pediatr Indones 2006;46:20-24].
\end{abstract}

Keywords: pediatric residency training, continuous content analysis, Indonesia

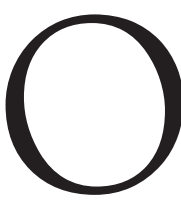

ver the last 20 years, higher education has changed dramatically. Four major changes were identified, i.e. a greatly expanded access to higher education and an increase in the diversity of students, increasing economic pressures with decreased government funding and the need to seek alternative funding sources, high demand for evidence of quality, and a movement to flexibly deliver. Each of these trends has a major impact on the provision of professional health education.

The expansion in access means an expansion in the number and types of professional health courses being offered. There is an increase in the number of students in professional health courses. The students come from a much wider educational background, ethnic and cultural base, age distribution, and gender mix. These variations provide both challenges and possibilities for the future. Particularly, they place new demands (e.g. for curriculum, management, and technological skills) on lecturers. ${ }^{8}$

From the Indonesian College of Pediatrics, Medical School, Gajah Mada University, Yogyakarta, Indonesia (SS); Medical Education Division, Medical School, Gajah Mada University, Yogyakarta, Indonesia (OE).

\footnotetext{
Reprint requests to: Srisuparyati Soenarto, MD, The Indonesian College of Pediatrics, Medical School, Gajah Mada University, Sardjito Hospital, Jl. Kesehatan no.1, Sekip Utara, Yogyakarta 55281, Indonesia. Tel. 62 274-587333 ext. 219, 62-274-7176995; Fax. 62-274-583745; Email: yatisoenarto@yahoo.com
} 
In pediatric residency training, the need to review the curriculum, based on the changes in the community, is clearly expressed in the core curriculum document. The nature of the curriculum is dynamic, changes are clearly needed from time to time according to community changes. ${ }^{2,3}$ The question is whether the residency training conducted in Indonesia today has been set up to answer the changing needs.

This study aimed to evaluate whether the current pediatric residency training program in Indonesia has met the changing as well as the community needs.

\section{Methods}

All centers in Indonesia (12 centers), each with pediatric training program, participated in the study. Heads of departments and staffs were included as respondents. The number of respondents varied for each institution, with a total of 42 respondents.

Structured questionnaires with open responses were selected to ensure the variety and flexibility of responses. The questions devised by the researcher were discussed and amended where necessary to ensure clarity and validity. The statements in the questionnaires included the following area: curriculum, training and educational system, and alumni achievement of educational objectives. Questionnaires were distributed to all centers and may be replicated if necessary.

The first 10 questionnaires were read several times, and from them three main categories were derived, i.e. training process, outcome evaluation, and program evaluation. Responses within each category were coded to form sub-categories. The sub-categories for training process were curriculum, theory and pratice, length of education, ratio of staff to students, financial condition, and educational system. Outcome evaluation is divided into three sub-categories according to the educational domain, i.e. knowledge, skills, and attitude.

\section{Results}

Curriculum content coverage was considered adequate by $80 \%$ of the respondents; however, it has not met international standards. It was suggested to be continuously updated in accordance with current national problems. The review of the curriculum should be conducted mutually by the medical school, College, pediatric department, ministry of health, and ministry of national education. At this stage respondents believe that the involvement of residents or community was not necessary. The master program added to the curriculum was advantageous for students.

Theory and practice during the training program was proportionally balanced. Additional knowledge and competence proposed by the respondents included mollecular biology, genetics, general skills, communication skills, and introduction to sophisticated instruments. Clinical discussions in various formats, such as problem-based learning, clinical problem solving, or round discussion were considerably increased to ensure that residents develop competence in clinical reasoning.

The present length of the study was fairly appropriate. Limiting the length may decrease the quality of the study. Respondents believe that students, not only develop their skills, but also mature during the process. The concept of an extended period of study was considered impractical.

The admittance selection for pediatric residency programs is nationally standardized. This practice is to maintain objectiveness and equality of opportunity for all candidates. By means of this system, the input of students can be controlled to preserve the ratio between staff and trainees at 1 staff for 2 students.

Tuition fee varied among the respondents which ranged from 5 to 25 million rupiahs per semester. If a double degree was included in the program, students were required to pay more, from a range of 6 to 35 million per semester. Cross subsidy was deemed important by the staff. Financial problems encountered by trainees during the program ought to be supported.

Lack of continuous assessment was not clearly described. Some respondents believed that there was an uncertain structure for the assessment. Materials for training and clinical activities had not yet been evaluated for their synchronization. Trainees should be supported during the entire training process, therefore counseling service should be included in the program.

Almost all staff responded that they were uncertain of their skills in supervising or in giving feedback. 
There was no such training to enhance their competence in clinical teaching. Some suggestions were directed to the Indonesian College of Pediatrics for improving the staff's capacity in supervision. This also applied to local supervisors in affiliated teaching hospitals. Most respondents were unable to describe their expectations for local supervisors. Moreover, they were unsure of the conditions in affiliated hospitals.

Graduate's knowledge was considered sufficient and fulfilled pediatric standards. This process was ensured through a national examination held by the College. All staff believed that the current program was better, particularly since the process was more structured and had additional teaching staff in each center. However, exposure to continuous professional development program was still required and considered essential in obtaining practice license or re-license.

The staff was mostly satisfied with the skills of graduates. Some staff doubted that current trainees have better learning experiences than that of the past since the patients and cases ratio has reduced due to the increased number of trainees. Courses to update skills were necessary although not specifically mentioned.

Regarding the attitude of the alumni, only $60 \%$ of the staff was satisfied. Their respond was that this depends on the personality of each trainee. Nevertheless, the placement of counselor in each program was anticipated to overcome these problems. Identified factors related to trainees' attitudes and behaviors included personality, such as norms, ethics, interpersonal relationship, empathy, altruist; attitude and behavior of staff or supervisor; learning environment; family problems; and value of discipline during education. However, more than $60 \%$ of the staff deemed that attitude development was not important; it was the responsibility of each trainee, or perhaps the selection in national level that should screen this tendency.

The staff agreed that the current program was different with that of the past. The objectives were clearer. The placements of trainees enable them to follow each division in a spiral fashion (at least three times during the training). The schedule was more rigid with the consequences of heavier burden for trainees. The addition of academic aspect was clearly reflected in the program. Some identified pitfalls should be improved, such as supervision and knowledge in each division which tends to cause incompatibility between staff members. The increase of trainees also created a dependant attitude from juniors towards their seniors.

\section{Discussion}

For the past decade, the pediatric College has broadened the spectrum of competency for residency to include academic skills, such as scientific philosophy, research methodology, biostatistics, and other related basic sciences. ${ }^{4}$ The residency program is designed as a combined degree program (residency training and master program) with the output of specialist and master degree. This integration process in professional training has been a global trend in medical education and is suggested in trilogy of international standard in medical education namely, World Federation for Medical Education (WFME). ${ }^{5}$ The combined education program is categorised as first professional degree (combination of $\mathrm{MD}$ and BSc in Medicine), second professional degree (combination of MSc and Specialist), and third professional degree (combination of $\mathrm{PhD} / \mathrm{Dr}$ and Specialist consultant/Sp). ${ }^{6}$

The members of Figure 5 showed that the deceleration of HAZ in the control group was bigger than in the treatment group. There was significant difference of HAZ changes between treatment group compared to the control group during 6 months of nutritional education $(\mathrm{p}=0.004)$.

The Indonesian College of Pediatrics recommends that all residency training programs should refer to Global Standards in Postgraduate Medical Education, published by WFME. ${ }^{5}$ Nine components are included to improve educational programs, i.e. mission and outcomes, training process, assessment of trainees, trainees, staffing, training settings and educational resources, evaluation of training process, governance and administration, and continuous renewal. Each component consists of two standards, i.e. basic standard which should be fulfilled and satisfied during evaluation process, while standard for quality development is the measurement for applying best practice for postgraduate medical education.

Although each country, including Indonesia, has a variety of teaching tradition, culture, social economic 
status, health problems, and health system, the core curriculum of residency training should consider the concept of Global Standards in Postgraduate Medical Education. The core is universal; however, each region may modify the curriculum according to their local needs which support the attainment of National Health Service. In practice, the core takes $80 \%$ of the curriculum while the rest consists of local wisdom.

The current mission and outcomes presented by the residency training programme has addressed national policy, however efforts to review the program to comply with international policy should be considered. The involvement of all stakeholders should be encouraged, particularly residency trainees and community. The Indonesian College of Pediatrics should make collaborations with competent authorities, e.g. Indonesian Medical Council to grant practice licenses only for graduates who have accomplished the national examination.

It is clear that emphasis in scientific method provides a strong point for the development of residency training program. Pollack ${ }^{7}$ showed that many residency programs now have a research requirement as a part of their educational experience. The purpose of this requirement is to introduce young physicians to the methods of medical research in hopes that they may better understand and evaluate the medical literature, add to the general fund of medical knowledge, and be stimulated into pursuing academic careers. However, the program should also focus on the expectations of consumers which rely on other soft skills, such as effective communication skills. Recommendations for educational institutions include placing greater emphasis on evidence-based approaches, ensuring specific training in quality management, and fostering skills in interdisciplinary planning and coordinating care for individual patients.

In terms of variation in tuition fee, there should be a thorough evaluation on the overall education cost with equal quality for different centers. National standards should be set up to control the educational administration accountability.

It has become widely accepted that assessment influences may determine what and how students learn. ${ }^{8}$ The analysis shows that the assessment of trainees has not been performed continously during their training years. Most emphasis is given to the final examination before their graduation. To enhance the advantage of assessment for learning, discussions at national level are required. The model of assessment should include a process and summative assessment with considerations of reliability and validity. As a consequence, the capacity of staff members to assess student performance needs to be improved. It is likely that training on assessment, technique in providing supervision and feedback is essential for students' learning, and ways to give feedback is also necessary.

The Indonesian College of Pediatrics has carried on regular selections at national level, a fact that should be encouraged. Managing the selection of trainees means that quality control and accountability of the process as well as maintaining the training process has been taken into account. Ratio of students to staff could be maintained in a proportional level. This is important to ensure the achievement of competency. More focus should be given to the trainees learning and working conditions. Trainees need friendly learning environment with plenty of opportunity for practicing skills. Therefore, national standards should be formulated to help teaching hospitals and its affiliate to fulfill the criteria as teaching hospital.

The involvement of trainees in planning the program should be encouraged, particularly to understand their needs and address their concern in learning.

The issue of staffing in residency training has been increasingly important. With the increased number of trainees, staff members should also multiply accordingly. All centers involve part-time staff from the affiliate teaching hospital as the supervisors fulfill the ratio criteria. This is the common practice anywhere. The College should find a mechanism to make position as supervisors attractive for the physician, if possible, which relates to their career development.

The number of hospitals involved in the training is enormous. Variation in quality for learning is large. A standard for teaching hospitals will help to prepare and equip themselves with all facilities needed. One example, that is clearly addressed, is the availability of information technology in the hospital. The present standards also enable the training program to be more flexible. Trainees may pursue any skills from different hospitals depending on the available resources. This will enable the possibility of credit transfer among the training centres. 
Program evaluation is a must for any training program to improve. The College should initiate program evaluation for a certain period of time. Evaluation should include all aspects of training, i.e. input, process, and output. A quality assurance process should be encouraged in each centre with the College as the coordinator.

There should not be uniformity in governance and administration, as long as it complies with the principles of accountability. Nevertheless, at national level, a mechanism for controlling the educational management, in general, should be set up.

The College has tried to keep up with the latest national health problems by reviewing the curriculum every 5 years. This activity should be expanded to include other aspects of teaching and learning. The present situation analysis serves as a preliminary effort to renew the training program with the evidence of data, not merely assumption.

In conclusion, the curriculum content of the training process is continuously updated in accordance with existing national problems, however, it is not yet considered of international standards. Additional knowledge, competence, and the present length of study is appropriate. The outcome of graduate knowledge is sufficient and fulfills the pediatric standards. Furthermore, the current program is different than that of the past since the objectives are clearer and the placements of trainees enable them to follow the each division at least three times.

\section{Acknowledgments}

This study was inspired by an invitation of the steering committee of the $13^{\text {th }}$ National Child Health Congress (KONIKA), In- donesian Association of Pediatricians, to speak at that congress, to which we offer our most sincere gratitude.

\section{References}

1. Higgs C, Neubauer D, Higgs J. The changing health care context: Globalization and social ecology. In: Higgs J, Edwards $\mathrm{H}$, editors. Educating beginning practitioners: Challenges for health professional education. $\mathrm{Ox}$ ford: Butterworth-Heinemann; 1999. p. 30-7.

2. Kolegium Ilmu Kesehatan Anak Indonesia. Kurikulum pendidikan dokter spesialis anak Indonesia 2000. Jakarta: Kolegium Ilmu Kesehatan Anak Indonesia; 2002. p. 1.

3. Pengurus Pusat Ikatan Dokter Anak Indonesia, Periode 2002-2005. Kompendium Ikatan Dokter Anak Indonesia. 2nd ed. Jakarta: Pengurus Pusat Ikatan Dokter Anak Indonesia; 2002. p. 6-7.

4. Komite Pendidikan Kedokteran Indonesia. Departemen Pendidikan Nasional Republik Indonesia. Pendidikan dokter spesialis di Indonesia. Jakarta: Departemen Pendidikan Nasional Republik Indonesia; 2005. p. 11-7.

5. World Federation for Medical Education. Postgraduate medical education: WFME global standards for quality improvement. Copenhagen: World Federation for Medical Education; 2003. p. 3-8.

6. Sastrowijoto S. Kebijakan nasional pengembangan pendidikan kedokteran di Indonesia KPKI, 2005. The Indonesian Journal of Medical and Health Profession Education 2005;1:1-10.

7. Pollack CV. Residency research requirements: Time for a reappraisal? J Emerg Med 1994;12:75-6.

8. Newble DI, Jaeger K. The effect of assessments and examinations on the learning of medical students. Medical Education 1983;17:165-71. 